18

\title{
Моделирование спектров люминесценции в сферических микрорезонаторах с излучающей оболочкой
}

\author{
(C) А.А. Дукин, В.Г. Голубев \\ ФТИ им. А.Ф. Иофрфре РАН, \\ 194021 Санкт-Петербург, Россия \\ e-mail: dookin@gvg.ioffe.ru
}

Поступила в редакцию 09.05.2021 г.

В окончательной редакции 16.06.2021 г.

Принята к публикации 23.06.2021 г.

\begin{abstract}
Проведено моделирование спектров люминесценции микрорезонаторной структуры, состоящей из сферического ядра малого диаметра $(3.5-6 \mu \mathrm{m})$, покрытого люминесцентной оболочкой с показателем преломления меньше, чем у ядра. Спектры люминесценции оболочки, радиальное распределение поля мод шепчущей галереи (МШГ) и параметры мод (длина волны, ширина, добротность) рассчитаны с использованием разложения поля электромагнитной волны в базисе векторных сферических гармоник и метода матриц переноса сферических волн. Изучена зависимость спектров люминесценции и параметров МШГ от геометрических и оптических параметров структуры - толщины оболочки, показателя преломления оболочки и диаметра ядра.
\end{abstract}

Ключевые слова: сферический микрорезонатор, люминесцентная оболочка, моды шепчущей галереи, моделирование спектров люминесценции.

DOI: $10.21883 / O S .2021 .10 .51499 .2266-21$

\section{Введение}

Благодаря своим уникальным оптическим свойствам сферические микрорезонаторы $[1,2]$ привлекают большое внимание в самых различных областях оптики [3-10]. Их уникальные свойства обусловлены модами шепчущей галереи (МШГ) - собственными модами электромагнитного поля сферического микрорезонатора. За счет полного внутреннего отражения МШГ распространяются по искривленной внутренней поверхности микросферы узким кольцом по экватору. МШГ могут обладать большой добротностью, высокой плотностью энергии, большим временем жизни и малым эффективным модовым объемом. Длины волн и ширины мод определяются размерами микросферы, а также диэлектрическими свойствами микросферы и окружающей среды. В микросферах с большим диаметром (десятки и сотни микрон) возможно получение МШГ с очень большой добротностью, вплоть до $10^{10}[11]$.

Микросферы с МШГ могут применяться в узкополосных фильтрах в системах спектрального уплотнения каналов, в фемтосекундных оптических переключателях, в перестраиваемых системах оптической задержки, для создания внешней оптической обратной связи в лазерах, для создания оптических волноводов из ряда близко расположенных микросфер, для фокусировки излучения с субволновым разрешением с помощью фотонных струй $[5,7]$.

Важной областью применения микросфер с МШГ является сенсорика. Микросферы большого диаметра (десятки и сотни микрометров) могут быть использованы для детектирования показателя преломления окружа- ющей среды, химических веществ, газов, биологических веществ, давления, смещения, влажности, температуры, электрического и магнитного полей и т.д. [3,8,12-15]. Пассивные микрорезонаторы, используемые как датчики, требуют высокоточного сопряжения с устройствами ввода-вывода сигнала, например оптическими волноводами, призмами и т.д., что ограничивает их применение. Активные микрорезонаторы (содержащие люминесцентные вещества), используемые в качестве датчиков, лишены этого ограничения, поскольку оптический сигнал (модулированные МШГ спектры люминесценции) возбуждается и детектируется дистанционно, что позволяет, например, вводить микрорезонатор в живую клетку. В высокодобротных микрорезонаторах, содержащих лазерную среду, при достаточно мощной оптической накачке возможно получение лазерного излучения в микросфере, что позволяет уменьшить ширину линии излучения, понизить предел детектирования поверхностной плотности адсорбируемого вещества [12], а также создать компактные и эффективные низкопороговые микролазеры [6]. Низкопороговые микролазеры на основе резонаторов с МШГ использовались для безметочного обнаружения отдельных вирусных частиц, обнаружения молекулярных электростатических изменений на биоинтерфейсах, а также для маркировки и отслеживания живых клеток по типу штрих-кода $[16,17]$.

Введение в микрорезонаторы широкополосных излучателей позволяет одновременно регистрировать набор линий люминесценции, соответствующий МШГ, что может быть использовано для увеличения чувствительности детектирования биологических веществ $[18,19]$. 
Светоизлучающие материалы могут вводиться как в саму микросферу [20-23], так и прикрепляться к ее поверхности [24-32]. На поверхность микросферы может также наноситься оболочка из светоизлучающего материала [33].

Для микросфер большого диаметра $(200 \mu \mathrm{m})$ нанесение оболочки с показателем преломления, большим, чем показатель преломления самой микросферы, позволило увеличить чувствительность датчиков показателя преломления внешней среды и адсорбции частиц [34]. Другой способ увеличения чувствительности люминесцентных датчиков заключается в использовании микросфер малого диаметра - менее $10 \mu \mathrm{m}[18,19]$.

Целью настоящей работы является моделирование спектров люминесценции микрорезонаторной структуры, состоящей из сферического ядра малого диаметра (3.5-6 $\mu \mathrm{m})$, покрытого люминесцентной оболочкой с показателем преломления меньше, чем у ядра. Спектры люминесценции оболочки, радиальное распределение поля МШГ и параметры мод (длина волны, ширина, добротность) будут рассчитаны с использованием разложения поля электромагнитной волны в базисе векторных сферических гармоник и метода матриц переноса сферических волн. Будет исследована спектральная зависимость интенсивности излучения от величины показателя преломления, толщины и величины поглощения оболочки. Также будет проанализирована зависимость параметров МШГ от геометрических и оптических параметров структуры - толщины оболочки, показателя преломления оболочки и диаметра ядра.

\section{Изучаемая микрорезонаторная структура и метод моделирования спектров люминесценции}

В настоящей работе будут проанализированы сферические микрорезонаторы типа ядро-оболочка с диаметром меньше $10 \mu \mathrm{m}$, в которых на сферическое оптически прозрачное диэлектрическое ядро нанесена люминесцентная оболочка с меньшим показателем преломления.

Микросферы малого диаметра (менее $10 \mu \mathrm{m}$ ) с МШГ могут использоваться для определения показателя преломления окружающей среды [35-37] и биомолекул $[18,19,38]$. При этом регистрируется сдвиг длины волны $\Delta \lambda$ и уширение мод, происходящие за счет изменения показателя преломления $n$ внешней среды и/или адсорбции на поверхности микросферы радиуса $R$ анализируемого вещества. Чувствительность датчика определяется как $\Delta \lambda / \lambda=\Delta R / R+\Delta n / n$, где $\lambda$ - длина волны моды, $\Delta R$ и $\Delta n-$ изменение радиуса и показателя преломления соответственно. Таким образом, чувствительность датчика (сдвиг линии в спектре) пропорциональна $1 / R$ и увеличивается с уменьшением радиуса микросферы, что обусловливает выгодность использования микросфер малого диаметра (вплоть до нескольких микрон). Несмотря на то, что в микросферах малого диаметра за счет большой кривизны поверхности радиационные потери больше и соответственно добротность МШГ меньше, чем в микросферах диаметром десятки и сотни микрон, применение микросфер малого диаметра приводит к выигрышу. В таких микросферах увеличение чувствительности компенсирует потерю разрешающей способности, связанную с уширением мод. Дополнительным преимуществом микросфер малого диаметра является упрощение спектра МШГ за счет того, что в спектре остаются только моды с $q=1$ и межмодовый интервал между ними увеличивается. Это облегчает идентификацию мод и позволяет детектировать и анализировать одновременно группу линий МШГ в одном спектре [19]. Продемонстрировано, что люминесцирующие микросферы с малым диаметром (порядка $2 \mu \mathrm{m}$ ) могут детектировать всего несколько фемтограмм вещества, осевшего на поверхность микросферы [18]. Такая высокая чувствительность связана как с изменением радиуса микросферы, так и с изменением показателя преломления за счет слоя вещества, адсорбированного на поверхности микросферы.

Сферическое ядро может быть синтезировано из оптически прозрачного аморфного кремнезема $\left(a-\mathrm{SiO}_{2}\right)$ с использованием методики, описанной, например, в работе [39]. Мезопористая оболочка может быть изготовлена из плотно упакованных трубок $a-\mathrm{SiO}_{2}$ и иметь систему монодисперсных цилиндрических пор с контролируемым средним диаметром (1.5-3.5 nm) [40-42]. Такая оболочка может иметь удельную поверхность пор до $1600 \mathrm{~m}^{2} / \mathrm{g}$, поры могут занимать до $60 \%$ от объема оболочки. За счет пористости показатель преломления оболочки меньше показателя преломления ядра, а площадь химически активной поверхности пор, к которым возможно присоединение светоизлучающих частиц и анализируемых веществ, намного превосходит площадь поверхности микросферы равного диаметра. Таким образом, за счет развитой сети взаимосвязанных пор и их большой удельной поверхности мезопористая оболочка может быть заполнена бо́льшим количеством светоизлучающих частиц и анализируемого вещества, чем то, которое может быть присоединено к поверхности сферы. В частности, продемонстрирована функционализация мезопористых материалов широкополосными излучателями, такими как органические красители [43-45] и углеродные наноточки $[46,47]$.

Преимуществом нанопористого кремнезема является возможность его использования в качестве матрицы для стабилизации излучательных свойств и пространственного разделения люминофоров, таких как люминесцентные красители [43,44], полупроводниковые квантовые точки [48], оксиды редкоземельных элементов [49], нанокристаллы перовскитов [50], углеродные наноточки [46]. Яркость люминесценции таких композитных частиц во многом обусловлена пространственным разделением молекул или наночастиц люминофора внутри частиц кремнезема, уменьшающим гашение люминесценции. Показано также, что при введении в нанопористые матрицы 
люминофоров, например углеродных наноточек [51] или наночастиц перовскита $\mathrm{CsPbr}_{3}[50,52]$, их излучательные характеристики не ухудшаются и остаются стабильными длительное время из-за уменьшения воздействия внешней среды на физико-химические свойства материалов. Увеличение интенсивности излучения люминофоров в нанопорах кремнеземных матриц достигнуто за счет плазмонного взаимодействия люминофоров с дополнительно введенными в поры матриц наночастицами благородных металлов [53].

Важно отметить, что кремнезем является экологически чистым и биосовместимым материалом, а технология его получения является дешевой и масштабируемой. Известно, что частицы нанопористого кремнезема нетоксичны, способны проникать через клеточную мембрану и накапливаться в клетках. Покрытие поверхности частиц специфическими лигандами обеспечивает за счет лиганд-рецепторного взаимодействия их адресную доставку в клетки. Данный прием широко используется при создании многофункциональных систем тераностики онкологических заболеваний на основе нанопористого кремнезема. Так, с помощью многофункциональных систем для тераностики, в которых используются композитные частицы на основе нанопористого кремнезема, можно осуществлять диагностику, высокотехнологичную терапию, адресную доставку токсичных химиопрепаратов, не нанося вреда здоровым тканям организма, проводить мониторинг доставки лекарств и результатов проведенной терапии [54-56]. Возможность создания микрорезонаторов и микролазеров из композитных материалов на основе нанопористого кремнезема открывает перспективы исследования внутриклеточных процессов in vitro и in vivo.

Для моделирования спектров люминесценции в микрорезонаторах использован метод расчета спектров излучения диполей, находящихся в сферическом слое [57]. В цитируемой работе рассматривалась структура, состоящая из центрального сферического ядра и многослойной системы концентрических сферических слоев, окружающих его. В одном из слоев структуры находятся излучающие диполи. Учитывая сферическую симметрию задачи, уравнения Максвелла рассматриваются в сферических координатах. Электромагнитное поле в каждом сферическом слое представляет сумму поля, создаваемого диполями в заданном слое, и поля, проникающего из соседних слоев через границы. Поле электромагнитной волны раскладывается в базисе векторных сферических гармоник. Электромагнитное поле в таком базисе имеет две поляризации (ТЕ и ТМ). Поле с ТЕ-поляризацией не имеет радиальной составляющей электрического поля, поле с ТМ-поляризацией не имеет радиальной составляющей магнитного поля (рис. 1,a). Условия непрерывности тангенциальных компонент электрического и магнитного полей на каждом сферическом интерфейсе между двумя соседними слоями позволяют связать амплитуды электрического и магнитного полей в соседних слоях с помощью матрицы переноса через этот интерфейс.

В настоящей работе смоделированы спектры излучения люминесцентной оболочки, которая нанесена на оптически прозрачное сферическое диэлектрическое ядро. Матрица переноса для всей структуры получается перемножением матриц переноса для внешней границы оболочки и границы между оболочкой и ядром. Она связывает амплитуды полей в ядре и во внешней среде с учетом излучения, которое создают диполи, расположенные внутри оболочки. Интенсивность, излучаемая вовне из оболочки, заполненной диполями со случайной ориентацией, рассчитывается с использованием матрицы переноса. Таким образом, моделируется сферическая оболочка, заполненная излучателями, например наноточками, молекулами или атомами. Используя разложение поля в базисе векторных сферических гармоник, находится пространственное распределение полей внутри и вне структуры. Все расчеты выполнялись с помощью программного пакета Mathematica.

Длины волн собственных мод электромагнитного поля в данной структуре находятся из условия равенства нулю матрицы переноса для всей структуры. Эти моды имеют асимптотику в виде убегающей на бесконечности сферической волны и характеризуются тремя числами: полярным индексом $l(l \geq 1)$, азимутальным индексом $m$ $(-l \leq m \leq l)$, радиальным индексом $q$ и двумя поляризациями (ТЕ и ТМ). Полярный индекс $l$ и азимутальный индекс $m$ описывают угловое распределение поля (число максимумов моды в экваториальном сечении равно $2|m|$, число максимумов моды в меридиональном сечении равно $l-|m|+1)$. Радиальный индекс $q$ соответствует числу максимумов моды, лежащих внутри структуры по радиусу. На рис. $1, b$ показано характерное распределение напряженности электрического поля по радиальной координате для ТЕ-поляризованной МШГ с $q=1$ на схематическом изображении сечения моделируемой структуры. Частоты мод не зависят от $m$, т.е. моды кратно вырождены по $m$. Для мод шепчущей галереи $m=l$ или $m$ близко к $l$, а значение $q$ не превышает нескольких единиц [1]. В дальнейшем МШГ будут обозначаться как $\mathrm{TE}_{l}^{q}$ или $\mathrm{TM}_{l}^{q}$, где ТЕ и ТМ - поляризации МШГ, $q$ и $l$ - соответствующие индексы.

\section{Результаты и их обсуждение}

На рис. 2 показаны спектры излучения люминесцирующей оболочки, нанесенной на сферическое ядро. На этом рисунке и на рисунках, приведенных далее, интенсивность излучения диполя внутри оболочки нормирована на интенсивность излучения диполя в однородной среде, у которой значения относительных диэлектрической и магнитной проницаемостей равны таковым в оболочке. На рис. 2, $a$ показаны спектры излучения оболочки отдельно для ТЕ- и ТМ-поляризаций излучения. Для каждой поляризации спектр состоит из большого 


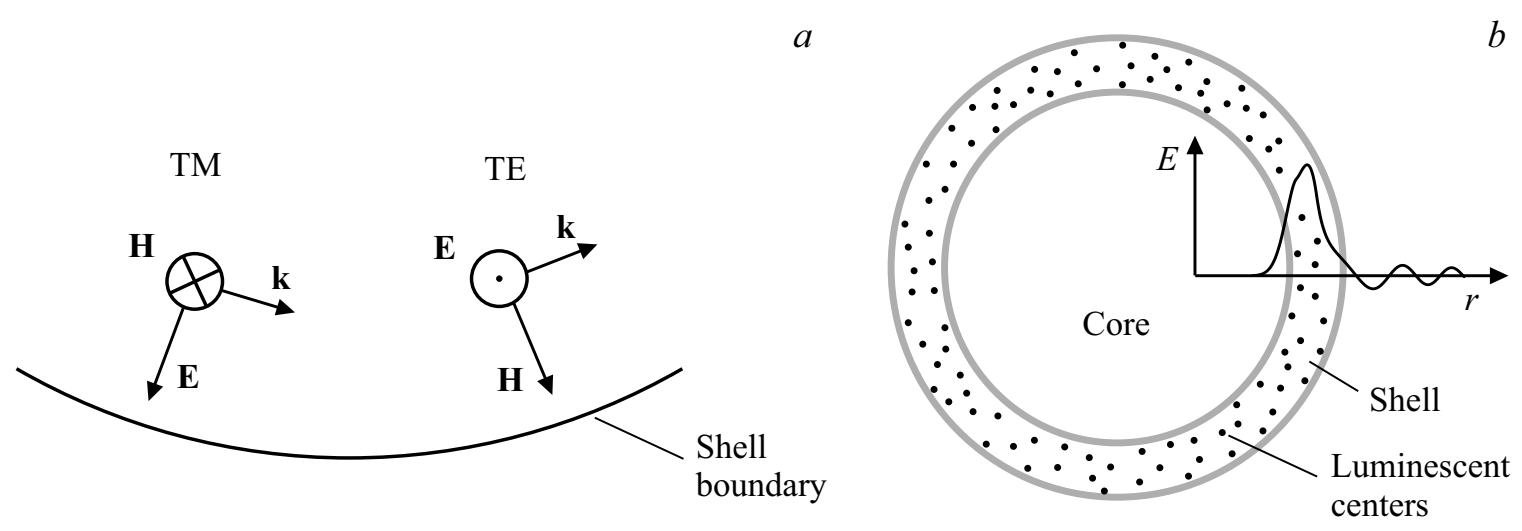

Рис. 1. (a) Изображение векторов электрического поля $\mathbf{E}$, магнитного поля $\mathbf{H}$ и волнового вектора $\mathbf{k}$ для ТЕ- и ТМполяризованных мод шепчущей галереи и фрагмента границы оболочки с внешней средой. $(b)$ Схематическое изображение сечения моделируемой структуры: две концентрические окружности показывают границы оболочки, на них наложен график, показывающий характерное распределение напряженности электрического поля $(E)$ по радиальной координате $(r)$ для ТЕ - поляризованной МШГ с $q=1$. Точками обозначены люминесцентные центры в оболочке.

количества упорядоченных пиков. Обозначения МШГ приведены над пиками. Все пики в спектре соответствуют МШГ с радиальным индексом $q=1$. Полярные индексы мод соседних пиков для каждой поляризации отличаются на единицу. Амплитуда пиков монотонно увеличивается, а ширина монотонно уменьшается при увеличении полярного индекса $l$. Амплитуда пиков для ТЕ-поляризованных МШГ несколько больше, а ширина несколько меньше, чем для ТМ-поляризованных МШГ с теми же полярным и радиальным индексами [58].

На рис. 2, $b$ приведены спектры излучения оболочки, включающие обе поляризации ТЕ и ТМ. Длины волн для ТМ-поляризованных мод близки к длинам волн ТЕполяризованных мод с теми же значениями индексов $l$ и $q$, поэтому в спектре излучения суммарного (неполяризованного) излучения пики сильно перекрываются (кривая 1, рис. 2,b). МШГ локализованы внутри структуры в виде узкого кольца, прилегающего изнутри к внешней поверхности оболочки. Волна распространяется вдоль этой границы с внешней средой и за счет полного внутреннего отражения от нее. Ширина мод уменьшается при увеличении оптического контраста (отношения показателей преломления оболочки и внешней среды) за счет увеличения коэффициента отражения от этой границы с внешней средой. Это обусловлено уменьшением радиационных потерь при отражении от границы и увеличением времени жизни фотона внутри структуры. Соответственно сужения пиков можно добиться, увеличив показатель преломления оболочки (кривая 2, рис. 2,b). Кроме того, ширина МШГ уменьшается при увеличении радиуса ядра [2]. Это связано с тем, что с увеличением радиуса уменьшается кривизна границы, вдоль которой бежит волна МШГ, и в результате уменьшаются излучательные потери. Таким образом, при увеличении радиуса ядра линии также сужаются и лучше разделяются (кривая 3, рис. 2,b). Сужение линий зависит от параметров оболочки, что будет обсуждаться позднее. На всех трех спектрах на рис. $2, b$ обозначены спектральные положения мод $\mathrm{TE}_{27}^{1}$ и $\mathrm{TM}_{27}^{1}$. Видно, что с увеличением показателя преломления оболочки и диаметра ядра положение пиков МШГ в спектрах сдвигается в длинноволновую область.

В случае пористой оболочки при заполнении пор, например, как люминесцирующими материалами, так и анализируемыми материалами, адсорбируемыми из внешней среды, показатель преломления оболочки увеличивается. Поэтому представляет интерес исследовать изменение спектров МШГ при увеличении показателя преломления оболочки. Поскольку в работе мы рассматриваем только оболочки с показателем преломления меньше, чем у ядра, то следует первоначально проанализировать предельный случай, когда показатель преломления оболочки равен показателю преломления ядра.

На рис. 3 показаны спектры излучения люминесцирующей оболочки толщиной $300 \mathrm{~nm}$ с показателем преломления 1.46, нанесенной на ядро диаметром $3.5 \mu \mathrm{m}$ с показателем преломления 1.46. Интенсивность излучения приведена в логарифмическом масштабе, для того чтобы были видны пики с малой интенсивностью, соответствующие модам с $q=2$. По сравнению с оболочкой той же толщины, но с меньшим показателем преломления 1.21 (рис. $2, b$ ) пики сдвинуты в длинноволновую область, ширины мод с $q=1$ уменьшились, и в результате линии с ТЕ- и ТМ-поляризацией не перекрываются. Например, для мод $l=27, q=1$ длина волны $\lambda\left(\mathrm{TE}_{27}^{1}\right)$ увеличилась с $520.3 \mathrm{~nm}$ до $590.4 \mathrm{~nm}$, добротность $(Q)$ выросла с 350 до 3830, ширина уменьшилась с 1.49 до $0.154 \mathrm{~nm}$. Разность длин волн ТЕ- и ТМ-поляризованных МШГ с одинаковыми индексами $\lambda\left(\mathrm{TE}_{27}^{1}\right)-\lambda\left(\mathrm{TM}_{27}^{1}\right)$ увеличилась c 4.1 до $11.5 \mathrm{~nm}$. Уменьшение ширины МШГ и, как следствие, увеличение добротности происходит за счет увеличения оптического контраста, как было отмечено ранее при обсуждении рис. 2. Общее число МШГ в 

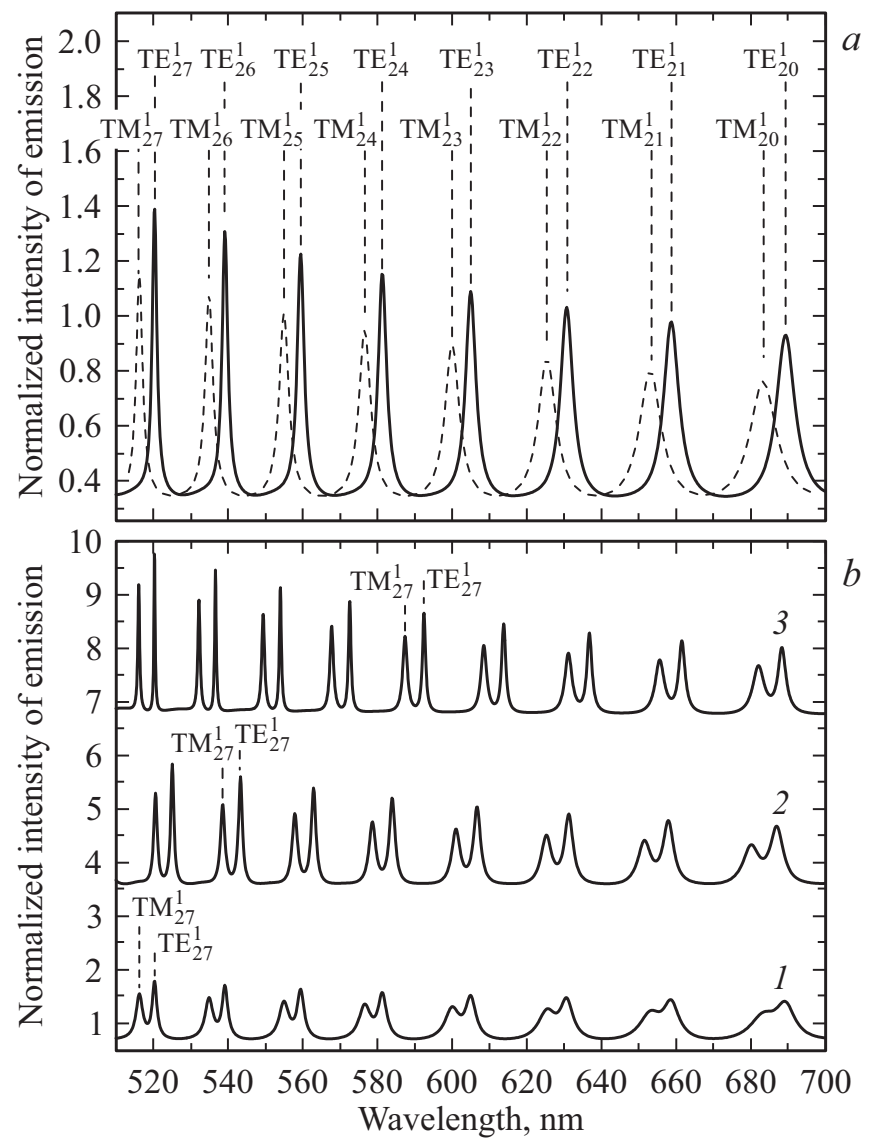

Рис. 2. Спектральные зависимости интенсивности излучения люминесцирующей оболочки, окружающей сферическое ядро. Показатель преломления ядра 1.46, толщина оболочки $300 \mathrm{~nm}$. (a) Сплошная линия - ТЕ-поляризация, штриховая линия - ТМ-поляризация, диаметр ядра $3.5 \mu \mathrm{m}$, показатель преломления оболочки 1.21. (b) Спектры неполяризованного излучения: $1-$ показатель преломления оболочки 1.21 , диаметр ядра $3.5 \mu \mathrm{m} ; 2-$ показатель преломления оболочки 1.31 , диаметр ядра $3.5 \mu \mathrm{m}$, спектр сдвинут вверх; 3 - показатель преломления оболочки 1.21 , диаметр ядра $4 \mu \mathrm{m}$, спектр сдвинут вверх. Вертикальные штриховые линии указывают положения МШГ. Обозначения мод указаны рядом с вертикальными линиями.

рассматриваемом спектральном интервале выросло, а межмодовый интервал уменьшился. Это объясняется тем, что за счет роста показателя преломления оболочки увеличилась оптическая длина пути, по которому бежит МШГ внутри резонатора [6].

Кроме того, в коротковолновой части спектра при показателе преломления оболочки 1.46 появилась группа линий, связанных с модами, у которых $q=2$. Их появление в спектре обусловлено уменьшением ширины этих мод и увеличением амплитуды соответствующих пиков вследствие увеличения оптического контраста (см. обсуждение рис. 2). У мод с $q=2$ меньше длина волны, намного меньше добротность $(Q)$ и амплитуда пика $(A)$ : $\lambda\left(\mathrm{TE}_{27}^{2}\right)=515.5 \mathrm{~nm}, Q\left(\mathrm{TE}_{27}^{2}\right)=168, A\left(\mathrm{TE}_{27}^{2}\right)=0.221$ по сравнению с модами с $q=1$ и тем же полярным индексом $l$, а именно $\lambda\left(\mathrm{TE}_{27}^{1}\right)=590.4 \mathrm{~nm}, Q\left(\mathrm{TE}_{27}^{1}\right)=3830$, $A\left(\mathrm{TE}_{27}^{1}\right)=19.9$. Таким образом, увеличение показателя преломления оболочки приводит к уменьшению ширины и росту добротности МШГ, к сдвигу мод в длинноволновую область спектра, к увеличению числа МШГ в выбранном спектральном диапазоне и к появлению мод c $q=2$.

Для того чтобы понять, как влияет увеличение диаметра ядра на спектр МШГ, рассчитаны спектры излучения оболочек толщиной $300 \mathrm{~nm}$ с показателями преломления 1.21 (рис. 4,a) и 1.46 (рис. 4,b), нанесенных на ядро диаметром $6 \mu \mathrm{m}$. По сравнению с диаметром ядра $3.5 \mu \mathrm{m}$ (рис. $2, a)$ количество мод с $q=1$ в спектральном интервале 550-650 nm увеличилось с 8 до 14. Увеличение диаметра ядра привело также к увеличению длины волны и добротности МШГ. Так, например, для моды $\mathrm{TE}_{27}^{1}$ длина волны увеличилась с 520.3 до $882.8 \mathrm{~nm}$, а добротность увеличилась соответственно с 350 до 1560. С увеличением размера резонатора интенсивность пиков нормированной люминесценции возрастает, так, например, для моды $\mathrm{TE}_{27}^{1}$ амплитуда пика увеличилась с 1.04 до 7.2 .

Во всем исследованном спектральном диапазоне $550-650 \mathrm{~nm}$ присутствуют не только моды с $q=1$, но и моды с $q=2$ с обеими поляризациями ТЕ и ТМ. При этом пики мод ТЕ- и ТМ-поляризаций с $q=1$ не перекрываются, в то время как пики мод ТЕ- и ТМполяризаций с $q=2$ значительно перекрываются. Добротность и амплитуда пиков мод с $q=1$ приблизительно на два порядка превосходят добротность и амплитуду

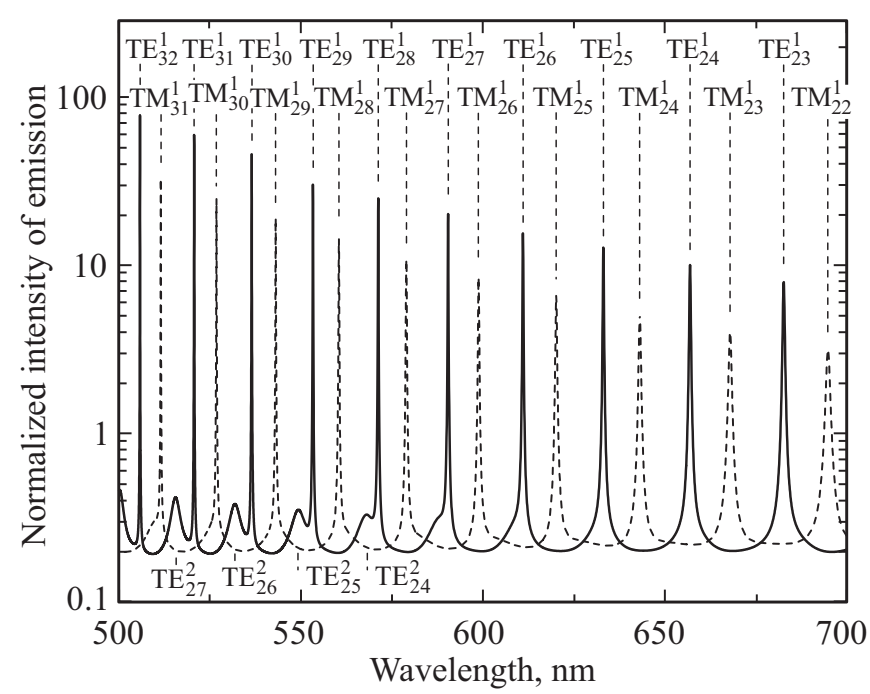

Рис. 3. Спектральные зависимости интенсивности излучения люминесцирующей оболочки толщиной $300 \mathrm{~nm}$ с показателем преломления 1.46 , окружающей ядро диаметром $3.5 \mu \mathrm{m}$ с показателем преломления 1.46. Сплошная линия $-\mathrm{TE}-$ поляризация, штриховая линия - ТМ-поляризация. Вертикальные штриховые линии указывают положения МШГ. Обозначения мод указаны рядом с вертикальными линиями. 

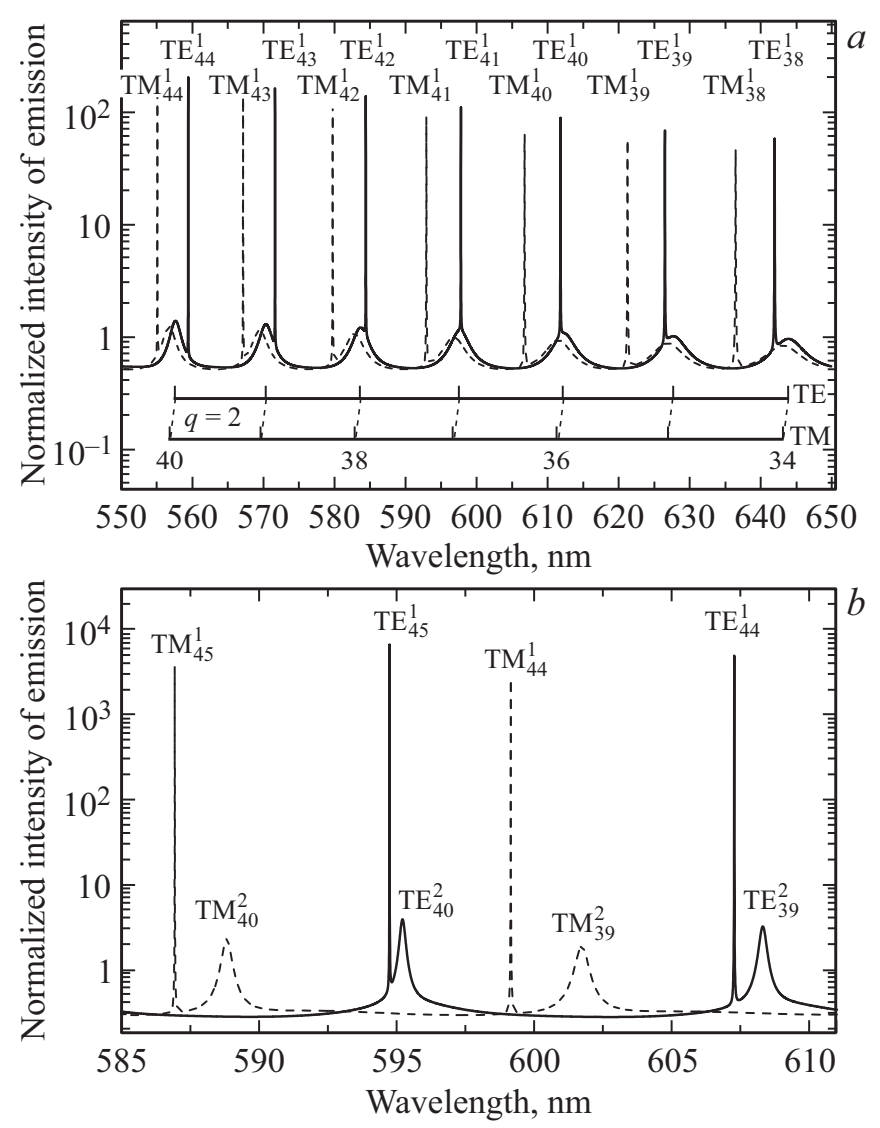

Рис. 4. Спектральные зависимости интенсивности излучения люминесцирующей оболочки толщиной $300 \mathrm{~nm}$, окружающей ядро диаметром $6 \mu \mathrm{m}$ с показателем преломления 1.46. Сплошные линии - ТЕ-поляризация, штриховые линии ТМ-поляризация. (a) Показатель преломления оболочки 1.21. (b) Показатель преломления оболочки 1.46. Обозначения МШГ указаны над пиками и под ними.

пиков мод с $q=2$ при тех же поляризациях и полярных индексах $l$.

На рис. 4, $b$ в более узком спектральном диапазоне показаны спектры излучения люминесцирующей оболочки толщиной $300 \mathrm{~nm}$ с показателем преломления 1.46, окружающей ядро диаметром $6 \mu \mathrm{m}$ с показателем преломления 1.46. Видно, что по сравнению с оболочкой с показателем преломления 1.21 (рис. 4,a) амплитуды пиков МШГ с $q=1$ и $q=2$ выросли более чем на порядок. Кроме того, ТЕ- и ТМ-поляризованные моды с $q=2$ не перекрываются. Добротность мод для оболочки с показателем преломления 1.46 также увеличивается в несколько раз по сравнению с добротностью мод для оболочки с показателем преломления 1.21, имеющих ту же поляризацию и те же индексы. Предельная величина добротности для МШГ с заданными значениями полярного и радиального индексов при фиксированном внешнем радиусе оболочки определяется максимально возможным показателем преломления оболочки. Поскольку в настоящей работе мы рассматриваем только оболочки с показателем преломления меньше, чем показатель преломления ядра, то максимально возможный показатель преломления оболочки - это показатель преломления ядра. Соответственно предельно достижимое значение добротности МШГ - это добротность МШГ в однородном шаре с радиусом, равным внешнему радиусу оболочки, и показателем преломления, равным показателю преломления ядра. Так, для моды $\mathrm{TE}_{27}^{1}$ предельная добротность $Q=3830$ в структуре с ядром диаметром $3.5 \mu \mathrm{m}$, показателем преломления 1.46 , толщиной оболочки $300 \mathrm{~nm}$ с показателем преломления 1.46 . Это значение добротности уменьшается, например, за

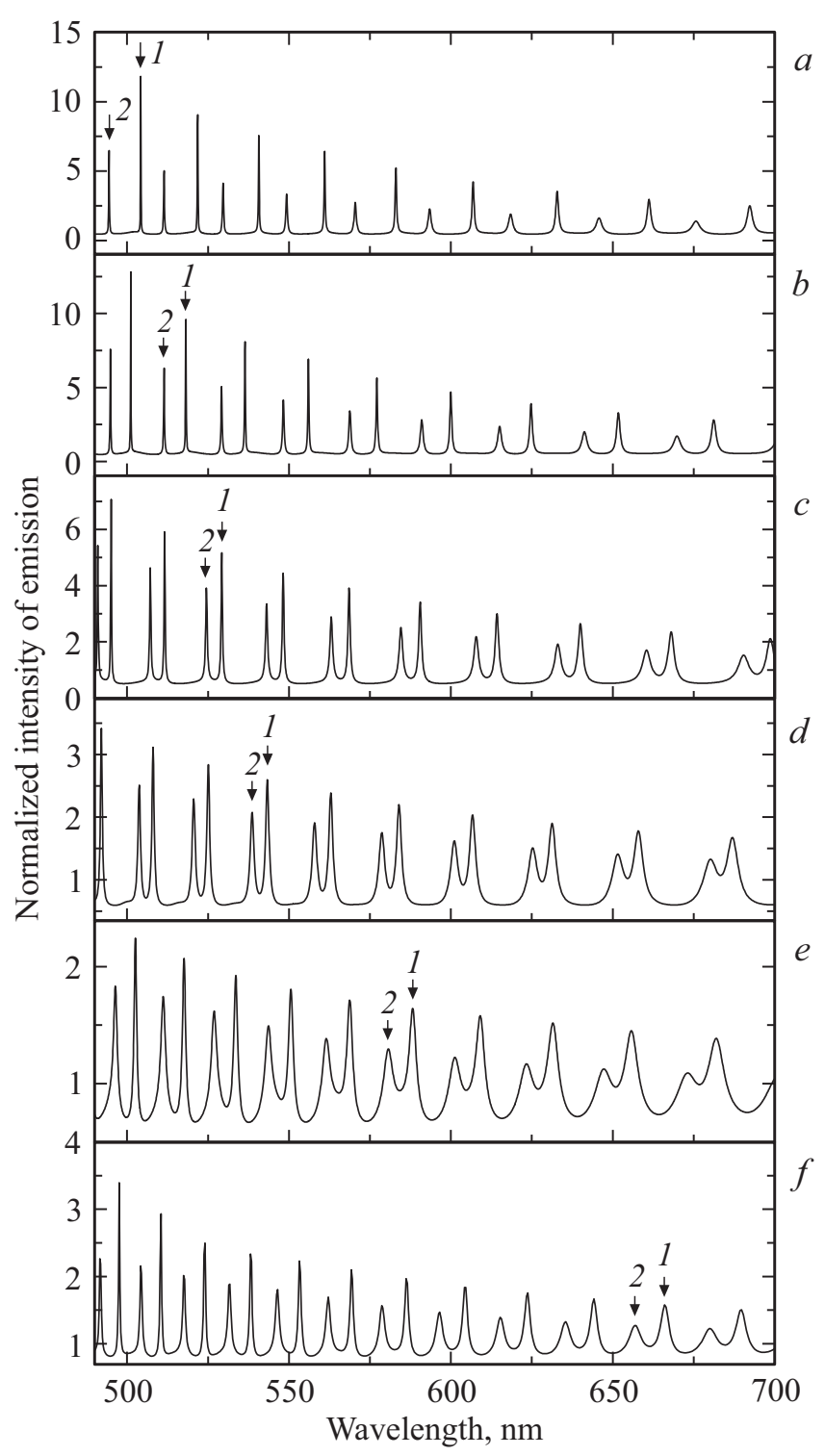

Рис. 5. Спектральные зависимости интенсивности излучения люминесцирующей оболочки с показателем преломления 1.31 , окружающей ядро диаметром $3.5 \mu \mathrm{m}$ с показателем преломления 1.46. Толщина оболочки: $a-1, b-100, c-200$, $d-300, e-500, f-800 \mathrm{~nm}$. Вертикальные стрелки 1 и 2 обозначают спектральные положения мод шепчущей галереи $\mathrm{TE}_{27}^{1}$ и $\mathrm{TM}_{27}^{1}$ соответственно. 


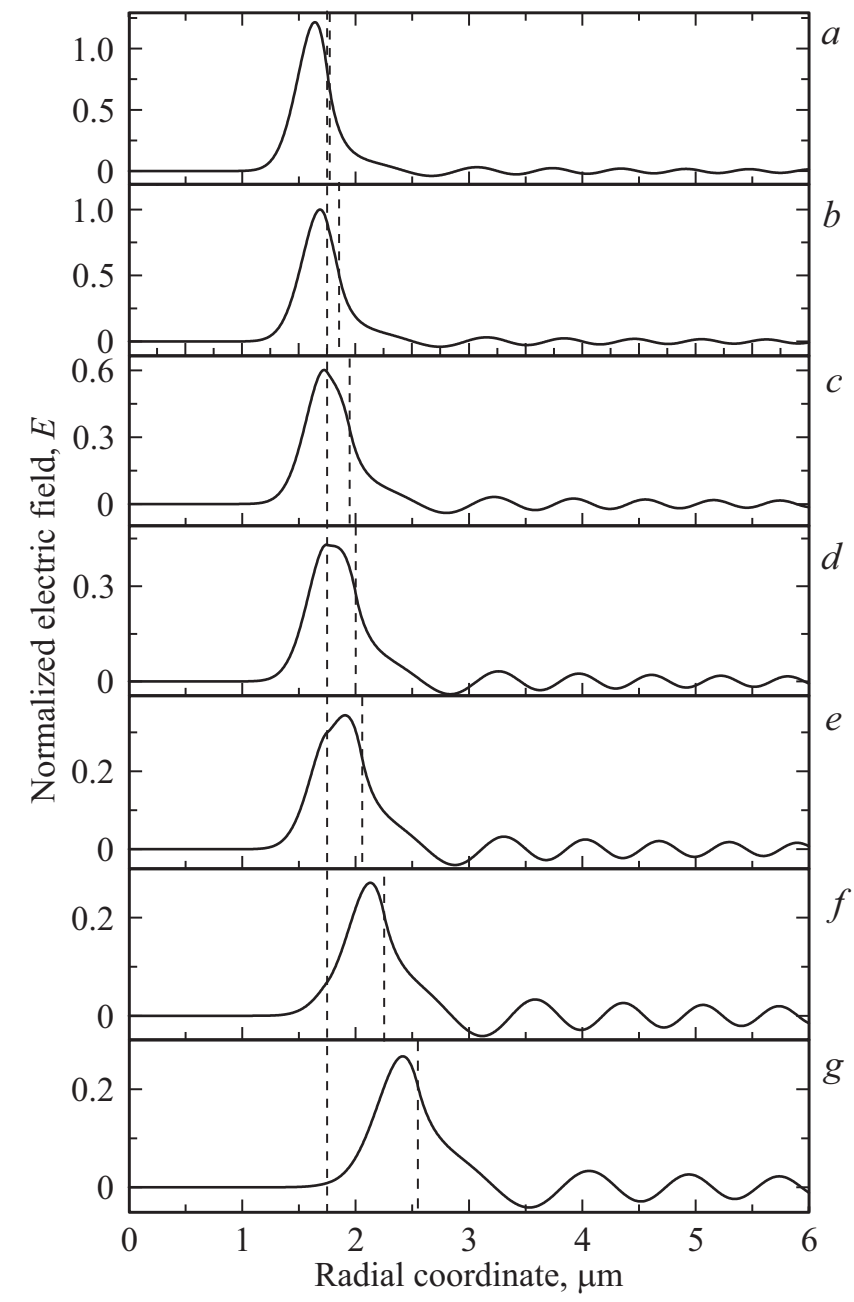

Рис. 6. Распределения напряженности электрического поля моды шепчущей галереи $\mathrm{TE}_{27}^{1}$ в микрорезонаторной структуре по радиальной координате. Оболочка с показателем преломления 1.31 нанесена на ядро диаметром $3.5 \mu \mathrm{m}$ с показателем преломления 1.46. Толщина оболочки: $a-1, b-100, c-$ $200, d-250, e-300, f-500, g-800 \mathrm{~nm}$. Вертикальные штриховые линии показывают границы оболочки с ядром и внешней средой. Профили поля нормированы так, что амплитуда убегающей волны равна 1.

счет поглощения в материале оболочки. Влияние поглощения на спектры люминесценции рассматривается ниже.

Рассмотрим зависимость параметров МШГ от толщины оболочки. Для этого выбрана структура, в которой ядро диаметром $3.5 \mu \mathrm{m} \mathrm{c}$ показателем преломления 1.46 окружено оболочкой с показателем преломления 1.31. Толщина оболочки изменяется в пределах от 1 до $800 \mathrm{~nm}$. Для такой структуры рассчитаны спектральные зависимости интенсивности излучения оболочки (рис. 5), распределение электрического поля МШГ по радиальной координате (рис. 6) и параметры (длина волны, ширина моды, добротность) ТЕ- и ТМ-мод (рис. 7) при различных значениях толщины оболочки.
На рис. 5 приведены спектральные зависимости интенсивности излучения из люминесцентной оболочки. Вертикальными стрелками отмечены спектральные положения мод $\mathrm{TE}_{27}^{1}$ и $\mathrm{TM}_{27}^{1}$. Видно, что с увеличением толщины оболочки длины волн МШГ с постоянным значением полярного индекса $l$ сдвигаются в длинноволновую область, пики уширяются, а их амплитуда уменьшается.

На рис. 6 приведено рассчитанное распределение напряженности электрического поля моды $\mathrm{TE}_{27}^{1}$ по радиальной координате для разных значений толщины оболочки в диапазоне от 1 до $800 \mathrm{~nm}$. График распределения напряженности электрического поля для моды $\mathrm{TM}_{27}^{1}$ повторяет основные особенности графика распределения для моды $\mathrm{TE}_{27}^{1}$, и поэтому не приводится. Внутри структуры поле МШГ распространяется как бегущая волна, которая испытывает полное внутреннее отражение от внешней границы оболочки, за внешней границей оболочки имеется небольшой участок эванесцентного, экспоненциально затухающего поля, которое потом переходит в сферическую волну, убегающую на бесконечность. Поскольку поле МШГ прижато к внешней границе структуры, то по мере увеличения толщины оболочки этот максимум сдвигается в область больших значений радиальной координаты. В диапазоне толщин 1-200 nm максимум электрического поля находится внутри ядра, в диапазоне толщин от $300 \mathrm{~nm}$ и более максимум находится внутри оболочки. При толщине оболочки $250 \mathrm{~nm}$ максимум поля переходит из ядра в оболочку. При толщине оболочки $800 \mathrm{~nm}$ и более практически все поле МШГ сосредоточено внутри оболочки. В этом случае МШГ очень близки к модам однородного шара с показателем преломления, равным показателю преломления оболочки, и с радиусом шара, равным внешнему радиусу оболочки.

На рис. 7 показаны рассчитанная длина волны, ширина моды, добротность и относительная разность длин волн $\left[\lambda\left(\mathrm{TE}_{27}^{1}\right)-\lambda\left(\mathrm{TM}_{27}^{1}\right)\right] /\left[\left(\lambda\left(\mathrm{TE}_{27}^{1}\right)+\lambda\left(\mathrm{TM}_{27}^{1}\right)\right) / 2\right]$ для двух мод $\mathrm{TE}_{27}^{1}$ и $\mathrm{TM}_{27}^{1}$ с одним и тем же постоянным полярным и радиальным индексом в зависимости от толщины оболочки. С увеличением толщины оболочки длина волны МШГ с заданными индексами монотонно увеличивается. При этом в диапазонах толщин $50-200 \mathrm{~nm}$ и 500-800 nm длины волн практически линейно зависят от толщины оболочки, но зависимости имеют разный наклон. Это можно объяснить тем, что в интервале толщин 0-200 nm максимум электрического поля МШГ лежит внутри ядра, и ядро оказывает решающий вклад в формирование МШГ. В интервале толщин более $500 \mathrm{~nm}$ максимум электрического поля мод лежит внутри оболочки, и решающий вклад в формирование МШГ оказывает оболочка.

Ширина пиков обеих ТЕ- и ТМ-поляризованных мод монотонно увеличивается с увеличением толщины оболочки (рис. 7,b). Кроме того, амплитуды максимумов радиального распределения поля (рис. 6) и амплитуды 


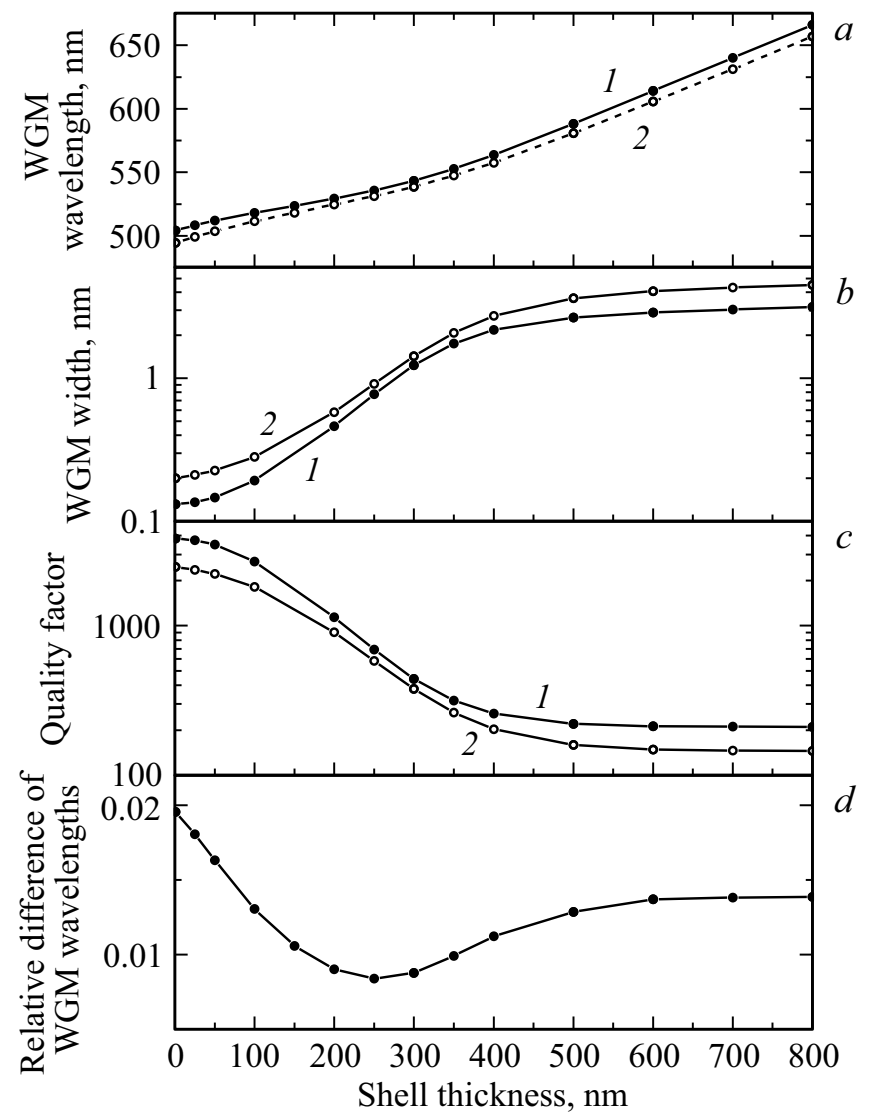

Рис. 7. Зависимости длины волны $(a)$, ширины $(b)$, добротности $(c)$ мод шепчущей галереи $\mathrm{TE}_{27}^{1}(1)$ и $\mathrm{TM}_{27}^{1}(2)$ от толщины оболочки; $(d)$ - зависимость относительной разности длин волн мод шепчущей галереи $\mathrm{TE}_{27}^{1}$ и $\mathrm{TM}_{27}^{1}$ $\left[\lambda\left(\mathrm{TE}_{27}^{1}\right)-\lambda\left(\mathrm{TM}_{27}^{1}\right)\right] /\left[\left(\lambda\left(\mathrm{TE}_{27}^{1}\right)+\lambda\left(\mathrm{TM}_{27}^{1}\right)\right) / 2\right]$ от толщины оболочки. Оболочка с показателем преломления 1.31 нанесена на ядро диаметром $3.5 \mu \mathrm{m}$ с показателем преломления 1.46 .

пиков (рис. 5) монотонно уменьшаются с ростом толщины. Это можно объяснить следующим образом. При очень малых значениях толщины оболочки ее влияние можно рассматривать несущественным и считать, что при распространении МШГ отражение происходит от границы между ядром и внешней средой - воздухом. Оптический контраст и соответственно коэффициент отражения для границы ядро-воздух больше, чем для границы оболочка-воздух. Поэтому при пренебрежимо малой толщине оболочки ширина МШГ минимальна, а добротность, амплитуда пика в спектре интенсивности излучения и амплитуда максимума поля максимальны. При толщинах оболочки, когда поле МШГ частично находится в ядре, а частично в оболочке, бегущая волна отражается от обеих границ, и они обе участвуют в формировании мод. С увеличением толщины оболочки поле МШГ постепенно переходит в оболочку (рис. 6), роль границы ядро-оболочка постепенно уменьшается, а роль границы оболочка-воздух в формировании мод возрастает. За счет исчезновения отражения от границы ядро- оболочка и за счет меньшего коэффициента отражения границы оболочка-воздух ширина МШГ увеличивается, амплитуды пиков в спектре излучения и максимума радиального распределения поля уменьшаются.

Ширина и добротность имеют сложную зависимость от толщины, что связано с постепенным переходом поля МШГ из ядра в оболочку. При этом ширина ТМ-поляризованных мод всегда больше ширины ТЕ-поляризованных мод, а добротность ТЕполяризованных мод всегда больше добротности ТМполяризованных мод во всем диапазоне исследованных толщин (рис. $7, b, c)$. В области толщин более $600 \mathrm{~nm}$ наблюдается практически линейный рост длины волны и ширины мод (рис. 7, $a, b$ ). В этой области толщин добротность выходит на насыщение и становится практически постоянной.

Разность длин волн ТЕ- и ТМ-поляризованных МШГ с одинаковыми индексами $l$ и $q$ заметно отличается для разных толщин (рис. 5). На рис. 7, $d$ приведена рассчитанная зависимость относительной разности длин волн мод $\mathrm{TE}_{27}^{1}$ и $\mathrm{TM}_{27}^{1}$ от толщины оболочки. Зависимость имеет заметный минимум (рис. $7, d$ ) при толщине оболочки $250 \mathrm{~nm}$. При этой толщине происходит переход максимума электрического поля моды $\mathrm{TE}_{27}^{1}$ из ядра в оболочку (рис. 6,d). При толщинах оболочки больше $600 \mathrm{~nm}$ величина относительной разности длин волн выходит на насыщение. Отметим, что для плоских волн минимум относительной разности длин волн ТЕ- и ТМполяризованных собственных мод был обнаружен ранее в планарных микрорезонаторах с распределенными брэгговскими отражателями [59].

Поглощение в материале оболочки может оказывать сильное влияние на параметры МШГ и на вид спектра излучения. На рис. 8 приведены спектры излучения оболочки при разной величине поглощения, которое задается мнимой частью диэлектрической проницаемости материала оболочки. Расчет проведен для люминесцирующей оболочки толщиной $300 \mathrm{~nm}$ с комплексным показателем преломления оболочки, окружающей ядро диаметром $6 \mu \mathrm{m}$ с показателем преломления 1.46. Вещественная часть комплексной диэлектрической проницаемости оболочки равна 1.72, мнимая часть меняется в диапазоне 0-0.05.

Увеличение поглощения в оболочке приводит к уменьшению амплитуды пиков МШГ и к их уширению, при этом спектральное положение пиков не меняется. Поглощение по-разному влияет на моды с разными радиальными индексами. Увеличение мнимой части диэлектрической проницаемости от 0 до 0.001 приводит к резкому уменышению амплитуды и уширению пиков МШГ с радиальным индексом $q=1$, при этом амплитуды пиков мод с радиальным индексом $q=2$ уменьшаются намного слабее (рис. $8, a-c$ ).

При значении мнимой части диэлектрической проницаемости, равном 0.01, пики МШГ с радиальным индексом $q=1$ практически полностью исчезают, а пики мод с радиальным индексом $q=2$ еще наблюдаются 


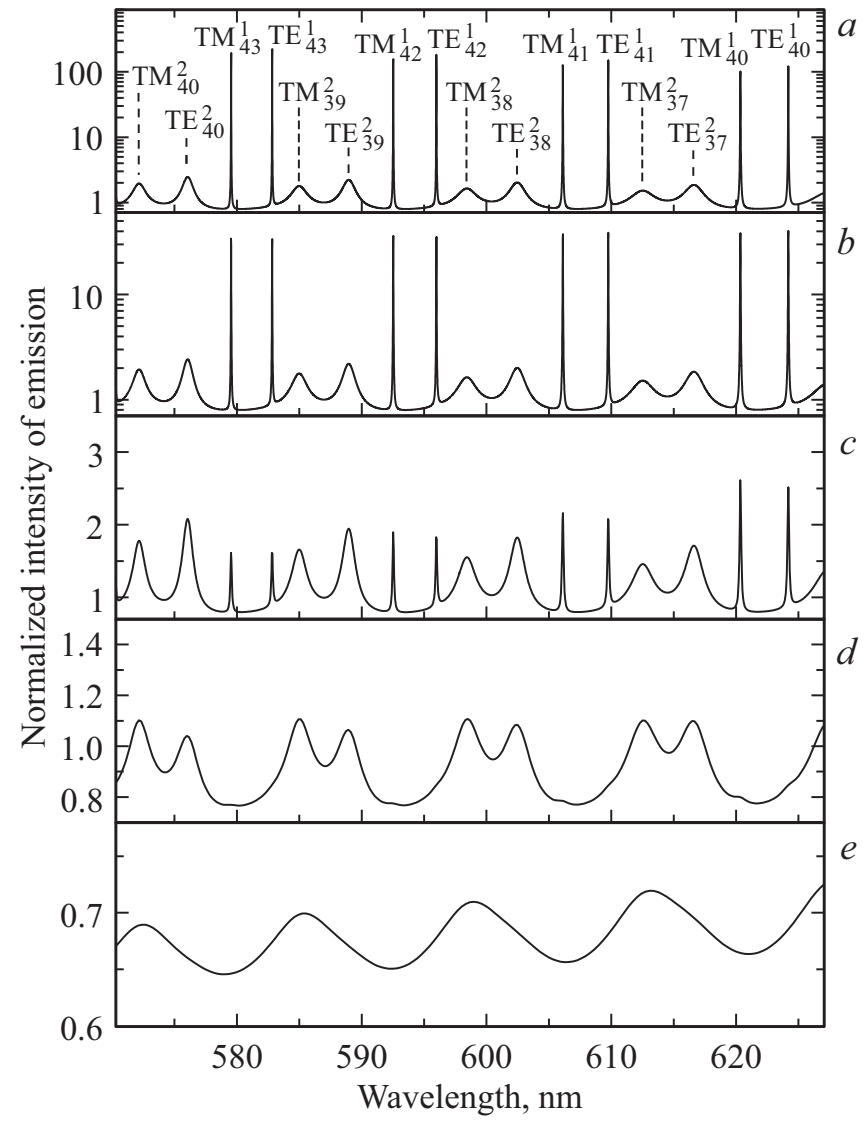

Рис. 8. Спектральные зависимости интенсивности неполяризованного излучения люминесцирующей оболочки толщиной $300 \mathrm{~nm}$, окружающей ядро диаметром $6 \mu \mathrm{m}$ с показателем преломления 1.46. Вещественная часть комплексной диэлектрической проницаемости оболочки равна 1.72, мнимая часть равна $0(a), 0.0001(b), 0.001(c), 0.01(d), 0.05(e)$. Вертикальные штриховые линии указывают положения МШГ. Обозначения МШГ указаны над пиками.

в спектре, но их амплитуда становится значительно меньше, чем при отсутствии поглощения, а сами пики уширяются (рис. 8,d). Таким образом, поглощение в оболочке полностью подавляет моды с $q=1$. При мнимой части диэлектрической проницаемости, равной 0.05 , пики мод с радиальным индексом $q=2$ уширяются настолько, что сливаются и становятся неразличимыми (рис. 8,e).

Также следует отметить, что при значении мнимой части диэлектрической проницаемости, равном 0.001, амплитуда пиков МШГ с $q=1$ уменьшается при увеличении полярного индекса (рис. $8, c$ ). При значении мнимой части диэлектрической проницаемости, равном 0.01 (рис. $8, d$ ), амплитуды ТМ-пиков становятся больше амплитуд ТЕ-пиков для мод с $q=2$ в противоположность тому, что было при меньшем значении мнимой части диэлектрической проницаемости в диапазоне 0-0.001 (рис. $8, a-c)$.
Таким образом, поглощение в оболочке по-разному влияет на МШГ с разной поляризацией, с различными радиальными и полярными индексами, а также с разной добротностью. Изменяя поглощение в оболочке, можно проводить селекцию МШГ с разными радиальными индексами и подавлять самые высокодобротные моды.

\section{Заключение}

В настоящей работе проведено моделирование спектров излучения микрорезонаторов типа ядро-оболочка, в которых на сферическое оптически прозрачное диэлектрическое ядро малого диаметра $(3.5-6 \mu \mathrm{m})$ нанесена люминесцентная оболочка с меньшим, чем у ядра, показателем преломления. Спектры люминесценции оболочки и распределение электрического поля МШГ по радиальной координате рассчитаны с использованием разложения поля электромагнитной волны в базисе векторных сферических гармоник и метода матриц переноса сферических волн. Для каждой поляризации (ТЕ и ТМ) спектр люминесценции состоит из большого количества упорядоченных пиков, соответствующих МШГ.

Исследованы зависимости спектров люминесценции от величины показателя преломления оболочки и диаметра ядра. Показано, что увеличение показателя преломления оболочки и диаметра ядра приводит к уменьшению ширины и росту добротности МШГ, к сдвигу мод в длинноволновую область спектра и появлению в спектре мод с радиальным индексом $q=2$.

Изучена зависимость параметров МШГ (длины волны, ширины, добротности) и радиального распределения напряженности электрического поля мод от толщины оболочки. Показано, что с увеличением толщины оболочки уменьшаются амплитуды пиков в спектре люминесценции и величины максимумов распределения электрического поля МШГ по радиальной координате. С увеличением толщины оболочки поле МШГ постепенно переходит из ядра в оболочку, поскольку именно на внешней границе оболочки электромагнитная волна испытывает полное внутреннее отражение, и эта граница играет ключевую роль в формировании МШГ. При этом роль границы ядро-оболочка в формировании мод уменьшается.

Рассмотрена зависимость величины относительной разности длин волн ТЕ- и ТМ-поляризованных мод с одинаковыми полярным и радиальным индексами от толщины оболочки. Обнаружено, что эта величина имеет минимум при значении толщины оболочки, при котором максимум радиального распределения напряженности электрического поля моды переходит из ядра в оболочку.

Исследована зависимость спектров люминесценции от величины поглощения оболочки. Увеличение поглощения в оболочке, задаваемого мнимой частью диэлектрической проницаемости материала оболочки, приводит к уменьшению амплитуды и уширению пиков, соответствующих МШГ, при этом спектральное положение пи- 
ков не меняется. Показано, что поглощение по-разному влияет на пики в спектре люминесценции в зависимости от добротности, поляризации, полярного и радиального индексов моды. При увеличении поглощения пики в спектре люминесценции, соответствующие высокодобротным модам с радиальным индексом $q=1$, могут быть полностью подавлены, тогда как пики, соответствующие низкодобротным модам с радиальным индексом $q=2$, все еще будут присутствовать в спектре.

\section{Финансирование работы}

Работа выполнена с использованием средств госбюджета по теме госзадания 0040-2019-0012.

\section{Конфликт интересов}

Авторы заявляют, что у них нет конфликта интересов.

\section{Список литературы}

[1] Ораевский А.Н. // Квант. электрон. 2002. Т. 32. № 5. C. 377; Oraevsky A.N. // Quantum Electron. 2002. V. 32. N 5. P. 377. doi 10.1070/QE2002v032n05ABEH002205

[2] Городецкий М.Л. Оптические микрорезонаторы с гигантской добротностью. М.: ФИЗМАТЛИТ, 2011. 416 с.

[3] Foreman M.R., Swaim J.D., Vollmer F. // Adv. Opt. Photon. 2015. V. 7. N 2. P. 168. doi 10.1364/AOP.7.000168

[4] François A., Zhi Y., Meldrum A. // Photonic Materials for Sensing, Biosensing and Display Devices. Springer International Publishing, 2016. V. 229. P. 237. doi 10.1007/978-3-319-24990-2

[5] Ward J., Benson O. // Las. Photon. Rev. 2011. V. 5. N 4. P. 553. doi 10.1002/lpor.201000025

[6] Chiasera A., Dumeige Y., Féron P., Ferrari M., Jestin Y., Nunzi Conti G., Pelli S., Soria S., Righini G.C. // Las. Photon. Rev. 2010. V. 4. N 3. P. 457 doi 10.1002/lpor.200910016

[7] Rakovich Y.P., Donegan J.F. // Las. Photon. Rev. 2010. V. 4. N 2. P. 179. doi 10.1002/lpor.200910001

[8] Righini G.C., Soria S. // Sensors. 2016. V. 16. N 6. P. 905. doi 10.3390/s16060905

[9] Cai L., Pan J., Zhao Y., Wang J., Xiao S. // Phys. Stat. Sol. A. 2020. V. 217. N 6. P. 1900825 . doi 10.1002/pssa.201900825

[10] Venkatakrishnarao D., Mamonov E.A., Murzina T.V., Chandrasekar R. // Adv. Opt. Mater. 2018. V. 6. N 18. P. 1800343. doi 10.1002/adom.201800343

[11] Gorodetskii M.L., Ilchenko V.S., Savchenkov A.A. // Opt. Lett. 1996. V. 21. N 7. P. 453. doi 10.1364/OL.21.000453

[12] Reynolds T., Riesen N., Meldrum A., Fan X., Hall J.M.M., Monro T.M., François A. // Las. Photon. Rev. 2017. V. 11. N 2. P. 1600265 . doi $10.1002 /$ lpor.201600265

[13] Vollmer F., Arnold S. // Nat. Methods. 2008. V. 5. N 7. P. 591. doi 10.1038/NMETH.1221

[14] Jiang X., Qavi A.J., Huang S.H., Yang L. // Matter. 2020. V. 3. N 2. P. 371. doi 10.1016/J.MATT.2020.07.008

[15] Zhi Y., Yu X.-C., Gong Q., Yang L., Xiao Y.-F. // Adv. Mater. 2017. V. 29. N 12. P. 1604920. doi 10.1002/adma.201604920

[16] Toropov N., Cabello G., Serrano M.P., Gutha R.R., Rafti M., Vollmer F. // Light Sci. Appl. 2021. V. 10. P. 42. doi 10.1038/s41377-021-00471-3
[17] Toropov N., Vollmer F. // Light Sci. Appl. 2021. V. 10. P. 77. doi 10.1038/s41377-021-00517-6

[18] Weller A., Liu F.C., Dahint R., Himmelhaus M. // Appl. Phys. B. 2008. V. 90. N 3-4. P. 561. doi 10.1007/s00340-007-2893-2

[19] Himmelhaus M., Krishnamoorthy S., Francois A. // Sensors. 2010. V. 10. N 6. P. 6257. doi 10.3390/s100606257

[20] Monte A.F.G., Rabelo D., Morais P.C. // J. All. Comp. 2010. V. 495. N 2. P. 436. doi 10.1016/j.jallcom.2009.11.040

[21] Dantham V.R., Bisht P.B. // J. Opt. Soc. Am. B. 2009. V. 26. N 2. P. 290. doi 10.1364/JOSAB.26.000290

[22] Mamonov E.A., Maydykovskiy A.I., Mitetelo N.V., Venkatakrishnarao D., Chandrasekar R., Murzina T.V. // Laser Phys. Lett. 2018. V. 15. N 3. P. 035401. doi $10.1088 / 1612-202 x / a a 9 b 23$

[23] Venkatakrishnarao D., Sahoo C., Vattikunta R., Annadhasan M., Naraharisetty S.R.G., Chandrasekar R. // Adv. Opt. Mater. 2017. V. 5. N 22. P. 1700695. doi 10.1002/adom.201700695

[24] Möller B., Artemyev M.V., Woggon U., Wannemacher R. // Appl. Phys. Lett. 2002. V. 80. N 18. P. 3253. doi 10.1063/1.1475364

[25] Götzinger S., Menezes L. de S., Benson O., Talapin D.V., Gaponik N., Weller H., Rogach A.L., Sandoghdar V. // J. Opt. B: Quantum Semiclass. Opt. 2004. V. 6. N 2. P. 154. doi 10.1088/1464-4266/6/2/005

[26] Fan X., Palinginis P., Lacey S., Wang H., Lonergan M.C. // Opt. Lett. 2000. V. 25. N 21. P. 1600. doi 10.1364/OL.25.001600

[27] Finlayson C.E., Sazio P.J.A., Sanchez-Martin R., Bradley M., Kelf T.A., Baumberg J.J. // Semicond. Sci. Technol. 2006. V. 21. N 3. P. L21. doi 10.1088/0268-1242/21/3/L01

[28] Melnikau D., Savateeva D., Chuvilin A., Hillenbrand R., Rakovich Y.P. // Opt. Expr. 2011. V. 19. N 22. P. 22280. doi 10.1364/OE.19.022280

[29] Mi Y., Zhang Z., Zhao L., Zhang S., Chen J., Ji Q., Shi J., Zhou X., Wang R., Shi J., Du W., Wu Z., Qiu X., Zhang Q., Zhang Y., Liu X. // Small. 2017. V. 13. N 42. P. 1701694. doi 10.1002/smll.201701694

[30] Schietinger S., Schröder T., Benson O. // Nano Lett. 2008. V. 8. N 11. P. 3911. doi $10.1021 / \mathrm{n} 18023627$

[31] Rakovich Y.P., Yang L., McCabe E.M., Donegan J.F., Perova T., Moore A., Gaponik N., Rogach A. // Semicond. Sci. Technol. 2003. V. 18. N 11. P. 914. doi 10.1088/0268$1242 / 18 / 11 / 302$

[32] Еуров Д.А., Стовпяга Е.Ю., Курдюков Д.А., Дукин А.А., Смирнов А.Н., Голубев В.Г. // ФТТ. 2020. Т. 62. № 10. C. 1690. doi 10.21883/FTT.2020.10.49922.102; Eurov D.A., Stovpiaga E.Yu., Kurdyukov D.A., Dukin A.A., Smirnov A.N., Golubev V.G. // Phys. Solid State. 2020. V. 62. N 10. P. 1898. doi 10.1134/S1063783420100054

[33] Грудинкин С.А., Донщов А.А., Феоктистов Н.А., Баранов М.А., Богданов К.В., Аверкиев Н.С., Голубев В.Г. // ФТП. 2015. Т. 49. № 10. С. 1415; Grudinkin S.A., Dontsov A.A., Feoktistov N.A., Baranov M.A., Bogdanov K.V., Averkiev N.S., Golubev V.G. // Semiconductors. 2015. V. 49. N 10. P. 1369. doi 10.1134/S1063782615100085

[34] Teraoka I., Arnold S. // J. Opt. Soc. Am. B. 2007. V. 24. N 3. P. 653. doi 10.1364/JOSAB.24.000653

[35] Zijlstra P., van der Molen K.L., Mosk A.P. // Appl. Phys. Lett. 2007. V. 90. N 16. P. 161101. doi 10.1063/1.2722695

[36] Pang S., Beckham R.E., Meissner K.E. // Appl. Phys. Lett. 2008. V. 92. N 22. P. 221108. doi 10.1063/1.2937209 
[37] Francois A., Himmelhaus M. // Sensors. 2009. V. 9. N 9. P. 6836. doi 10.3390/s90906836

[38] Beier H.T., Coté G.L., Meissner K.E. // Ann. Biomed. Eng. 2009. V. 37. N 10. P. 1974. doi 10.1007/s10439-009-9713-2

[39] Трофимова Е.Ю., Алексенский А.Е., Грудинкин С.А., Коркин И.В., Курдюков Д.А., Голубев В.Г. // Коллоидный журн. 2011. Т. 73. № 4. С. 535; Trofimova E.Y., Aleksenskii A.E., Grudinkin S.A., Korkin I.V., Kurdyukov D.A., Golubev V.G. // Colloid J. 2011. V. 73. N 4. P. 546. doi 10.1134/S1061933X11040156

[40] Trofimova E.Yu., Kurdyukov D.A., Yakovlev S.A., Kirilenko D.A., Kukushkina Yu.A., Nashchekin A.V., Sitnikova A.A., Yagovkin M.A., Golubev V.G. // Nanotechnol. 2013. V. 24. N 15. P. 155601. doi 10.1088/0957-4484/24/15/155601

[41] Kurdyukov D.A., Eurov D.A., Kirilenko D.A., Kukushkina J.A., Sokolov V.V., Yagovkina M.A., Golubev V.G. // Micro. Mesopor. Mater. 2016. V. 223. P. 225. doi 10.1016/j.micromeso.2015.11.018

[42] Kurdyukov D.A., Eurov D.A., Kirilenko D.A., Sokolov V.V., Golubev V.G. // Micro. Mesopor. Mater. 2018. V. 258. P. 205. doi 10.1016/j.micromeso.2017.09.017

[43] Трофимова Е.Ю., Грудинкин С.А., Кукушкина Ю.А., Курдюков Д.А., Медведев А.В., Яговкина М.А., Голубев В.Г. // ФTT. 2012. T. 54. № 6. C. 1220; Trofimova E.Yu., Grudinkin S.A., Kukushkina Yu.A., Kurdyukov D.A., Medvedev A.V., Yagovkina M.A., Golubev V.G. // Phys. Solid State. 2012. V. 54. N 6. P. 1298. doi 10.1134/S1063783412060339

[44] Cho E.-B., Volkov D.O., Sokolov I. // Small. 2010. V. 6. N 20. P. 2314. doi 10.1002/smll.201001337

[45] Kalaparthi V., Palantavida S., Sokolov I. // J. Mater. Chem. C. 2016. V. 4. N 11. P. 2197. doi 10.1039/c5tc04221f

[46] Nelson D.K., Razbirin B.S., Starukhin A.N., Eurov D.A., Kurdyukov D.A., Stovpiaga E.Yu., Golubev V.G. // Opt. Mater. 2016. V. 59. P. 28. doi 10.1016/j.optmat.2016.03.051

[47] Eurov D.A., Kurdyukov D.A., Medvedev A.V., Kirilenko D.A., Tomkovich M.V., Golubev V.G. // Nanotechnol. 2021. V. 32. N 21. P. 215604. doi 10.1088/1361-6528/abe66e

[48] Sathe T.R., Agrawal A., Nie S. // Anal. Chem. 2006. V. 78. N 16. P. 5627. doi 10.1021/ac0610309

[49] Eurov D.A., Kurdyukov D.A., Kirilenko D.A., Kukushkina Yu.A., Nashchekin A.V., Smirnov A.N., Golubev V.G. // J. Nanopart. Res. 2015. V. 17. N 2. P. 82. doi 10.1007/s11051015-2891-y

[50] Ushakova E.V., Cherevkov S.A., Sokolova A.V., Li Y., Azizov R.R., Baranov M.A., Kurdyukov D.A., Stovpiaga E.Y., Golubev V.G., Rogach A.L., Baranov A.V. // Chemnanomat. 2020. V. 6. N 7. P. 1080. doi 10.1002/cnma.202000154

[51] Stepanidenko E.A., Khavlyuk P.D., Arefina I.A., Cherevkov S.A., Xiong Y., Döring A., Varygin G.V., Kurdyukov D.A., Eurov D.A., Golubev V.G., Masharin M.A., Baranov A.V., Fedorov A.V., Ushakova E.V., Rogach A.L. // Nanomaterials. 2020. V. 10. N 6. P. 1063. doi 10.3390/nano10061063

[52] Cherevkov S., Azizov R., Sokolova A., Nautran V., Miruschenko M., Arefina I., Baranov M., Kurdyukov D., Stovpiaga E., Golubev V., Baranov A., Ushakova E. // Nanomaterials. 2021. V. 11. N 1. P. 119. doi 10.3390/nano11010119

[53] Курдюков Д.А., Еуров Д.А., Медведев А.В., Голубев В.Г. // Письма в ЖТФ. 2020. Т. 46. № 18. С. 42. doi 10.21883/PJTF.2020.18.50002.18402; Kurdyukov D.A., Eurov D.A., Medvedev A.V., Golubev V.G. // Tech. Phys. Lett. 2020. V. 46. N 9. P. 928. doi 10.1134/S1063785020090229
[54] Tang F., Li L., Chen D. // Adv. Mater. 2012. V. 24. N 12. P. 1504. doi 10.1002/adma.201104763

[55] Colilla M., González B., Vallet-Regí M. // Biomater. Sci. 2013. V. 1 N 2. P. 114. doi 10.1039/C2BM00085G

[56] He Q., Shi J. // Adv. Mater. 2014. V. 26. N 3. P. 391. doi 10.1002/adma.201303123

[57] Hall J.M.M., Reynolds T., Henderson M.R., Riesen N., Monro T.M., Shahraam Afshar V. // Opt. Expr. 2017. V. 25. N 6. P. 6192. doi 10.1364/OE.25.006192

[58] Righini G.C., Dumeige Y., Féron P., Ferrari M., Nunzi Conti G., Ristic D., Soria S. // Nuovo Cimento. 2011. V. 34. N 7. P. 435. doi $10.1393 / \mathrm{ncr} / \mathrm{i} 2011-10067-2$

[59] Dukin A.A., Feoktistov N.A., Golubev V.G., Medvedev A.V., Pevtsov A.B., Sel'kin A.V. // Phys. Rev. E. 2003. V. 67. N 4. P. 046602. doi 10.1103/PhysRevE.67.046602 